\title{
Changes in Tropical Clouds and Radiation
}

Two potentially important papers by Wielicki et al. (1) and Chen et al. (2) dealt with aspects of how clouds and radiation vary and change, and whether climate models simulate the changes correctly. There is ample prior evidence suggesting that models have difficulties in correctly simulating clouds, and clouds are regarded as the biggest source of uncertainty in reports by the Intergovernmental Panel on Climate Change (IPCC) (3). However, an alternative interpretation of the disagreements shown between observations and models is that the analyses of the observations may be flawed.

Making observations from space that are stable over time is difficult. Most satellites last only a few years before they are replaced, orbits of satellites decay, and heating extremes are experienced as the satellite platform moves into and out of sunlight. Therefore, calibration and ground truth validation are vital for accurate measurements. In the case of outgoing longwave radiation (OLR), there are no trends observed like those by the Earth Radiation Budget Satellite (ERBS) $(1)$ in the operational NOAA series of satellites $(4,5)$. It seems likely that the highly unusual OLR observations during the 1997-98 El Niño were real (6) and failure of models to represent this climatic variation suggest their inadequacy. Because values from instruments on different satellites cannot be trusted without overlapping measurements, the real-
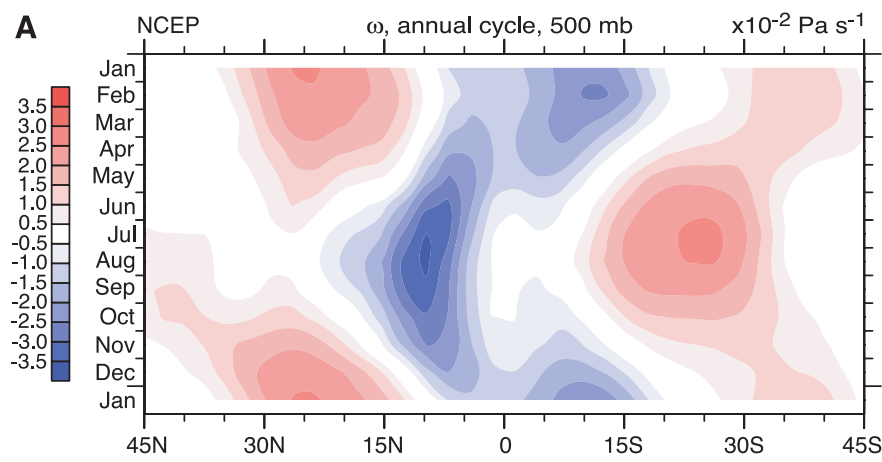

B
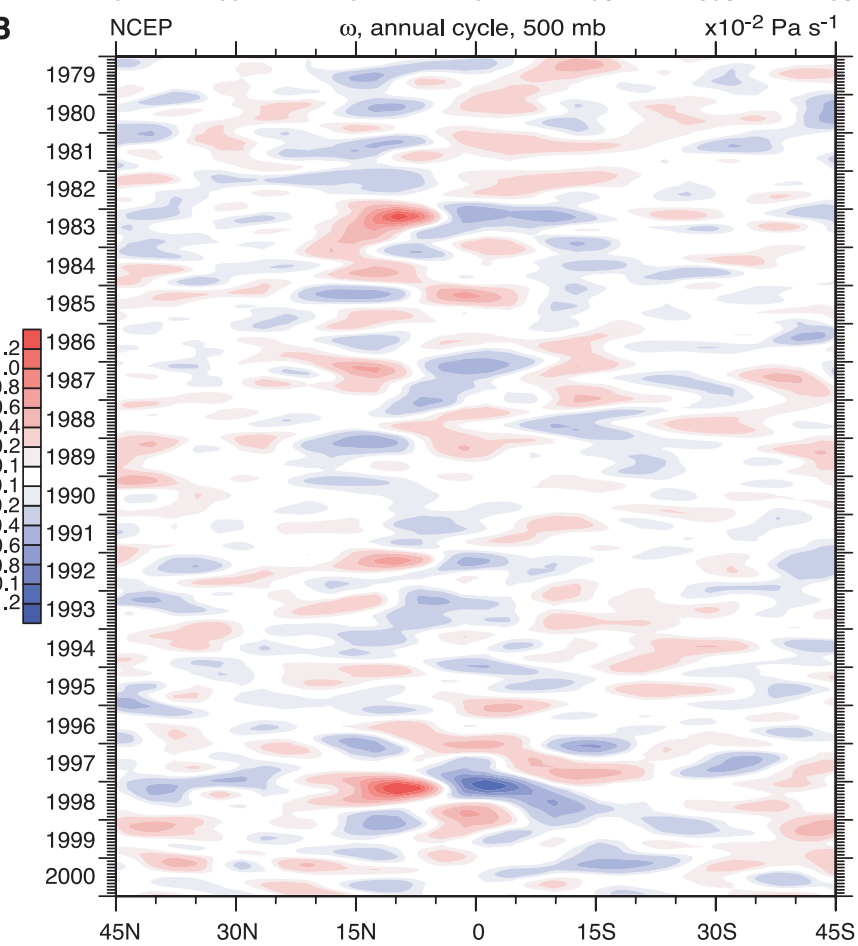

Fig. 1. Latitude-time sections for (A) mean annual cycle and (B) anomalies of the zonally averaged

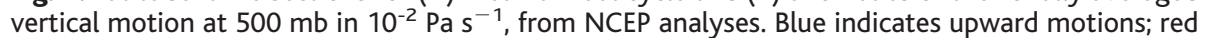
indicates downward motions. ity of the increase in OLR in the 1990s hinges on the continuity of the ERBS measurements. However, there was a three-month hiatus in those measurements in 1993, after which substantial changes in calibration occurred and an offset of $2.5 \mathrm{~W} \mathrm{~m}^{-2}$ was introduced (7). Without that offset, the decadal increase in OLR would not exist. At the very least, this raises questions about the reality of the decadal variation reported in $(1,2)$.

Another contributing factor to a flawed analysis could be the way the data were processed. Because the ERBS satellite precesses with about a 36-day period, monthly averaged data alias the diurnal cycle onto 6 -month periods $(5 \times 36$ days $)$. Hence, it is likely that the appearance of the semiannual cycle in the record is spurious and a result of interference between the diurnal and annual cycles. It is not surprising that this scenario is not simulated by current climate models.

Chen et al. (2) suggested that the hydrological cycle is changing, that the Hadley and Walker cells are strengthening, and that other variables, including upper-tropospheric humidity and cloudiness, are changing in consistent ways. Changes in satellites, however-specifically, the late 1991 introduction of NOAA12- have introduced spurious variability into the cloud record. In addition, the challenge is to ensure that the changes in the variables are quantitatively consistent and not transient. A latitude-time series of the zonally averaged mean annual cycle and the anomalies of the 500 millibar (mb) vertical motion [Fig. 1 and $(8,9)$ ] from the National Centers for Environmental Prediction (NCEP) reanalyses (10) for 1979 to 2000 place the Chen et al. period of January 1985 to August 1994 in context. Because a prolonged but modest El Niño event occurred from mid-1990 to mid-1995 (11-13), changes found by (2) are real, but small and short-lived. El Niño and interannual variability are dominant regardless of the analysis source (10), and decadal trends are not significant.

The overall conclusion is that there is great difficulty in obtaining reliable time series from space unless satellite records overlap, the orbits are stabilized, and calibration and validation are given much more attention. The results presented by Wielicki et al. and Chen et al. reveal the shortcomings in the current climate observing system and the need for a new approach to making stable homogeneous climate observations.

Kevin E. Trenberth Climate Analysis Section National Center for Atmospheric Research Boulder, CO 80307, USA E-mail: trenbert@ucar.edu

References and Notes

1. B. A. Wielicki et al., Science 295, 841 (2002).

2. J. Chen, B. E. Carlson, A. D. Del Genio, Science 295 838 (2002). 


\section{TECHNICALCOMMENTS}

3. IPCC, Climate Change 2001, The Scientific Basis, J. T. Houghton et al., Eds. (Cambridge Univ. Press, Cambridge, 2001), p. 881.

4. L. E. Lucas et al., J. Clim. 14, 2583 (2001)

5. K. E. Trenberth, D. P. Stepaniak, J. M. Caron, J. Geophys. Res. 107, 10.1029/2000JD000297 (2002).

6. R. D. Cess et al., Geophys. Res. Lett. 28, 4547 (2001).

7. The offset was based upon calibration against the blackbody on board the satellite (14). Observations of the total solar irradiance from the same satellite also changed by about $1 \mathrm{~W} \mathrm{~m}^{-2}$ relative to other measurements about this time.

8. K. E. Trenberth, D. P. Stepaniak, J. M. Caron, J. Clim. 13, 3969 (2000)

9. The poleward edges of the upward branch of the Hadley circulation migrate from $20^{\circ} \mathrm{S}$ to $20^{\circ} \mathrm{N}$ with the seasons and were not accurately depicted in (2).

10. The reanalyses are from National Centers for Environmental Prediction (NCEP)/National Center for Atmospheric Research and European Centre for Medium Range Weather Forecasts (ECMWF). For NCEP, they are extended using the same analysis system. Anomalies are defined as departures from the mean annual cycle. The monthly anomaly time series has been smoothed with a 1/24 (1-3-5-6-5-3-1) filter that suppresses subannual fluctuations but shows interannual variability. For the 1979 to 1993 period, the monthly anomalies from NCEP are correlated with values from ECMWF about 0.6 from $20^{\circ} \mathrm{N}$ to $20^{\circ} \mathrm{S}$ and exceed 0.9 in the extratropics.

11. K. E. Trenberth, T. J. Hoar, Geophys. Res. Lett. 23, 57 (1996).

12. K. E. Trenberth, Bull. Am. Meteorol. Soc. 78, 2771 (1997).

13. The El Niño from 1990 to 1995 could also be interpreted as a series of three El Niños in close succession.

14. B. A. Wielicki, personal communication.

6 February 2002; accepted 25 April 2002

Response: We have carefully considered Trenberth's concerns regarding our papers $(1,2)$ and have reached the following conclusions

First, Trenberth is concerned that there was an ERBS calibration shift while the instrument was powered down for 4 months from July to November 1993, during a spacecraft battery system anomaly. When the instrument resumed operation, the total channel offsets (zero-level instrument reading) used to provide longwave (LW) fluxes had dropped by about $3 \mathrm{~W} \mathrm{~m}^{-2}$, roughly the magnitude of the decadal tropical mean increase in LW flux. It is to be expected from both the physics of active-cavity instruments and past experience that changes in offsets will occur after extended power-down periods because of the change in thermal state of the instrument $(3,4)$. The validity of the ERBS offset change in late 1993 was verified using two independent tests. Offsets determined using the onboard blackbody were verified by direct observations of deep space four times between 1984 and 1999. All four cases agreed with blackbody-determined offsets to within 0.3 to $0.7 \mathrm{~W} \mathrm{~m}^{-2}$, while preand post-1993 values agreed within $0.5 \mathrm{~W}$ $\mathrm{m}^{-2}$. In addition, 6-month averages of Advanced Very High Resolution Radiometer (AVHRR), High-Resolution Infrared Radiation Sounder (HIRS), and ERBS LW fluxes before and after the period in question agreed to within $0.5 \mathrm{~W} \mathrm{~m}^{-2}$. For a 6-month period, AVHRR and HIRS orbit and calibration drift are expected to be small. We conclude that there is no evidence that a change in the ERBS calibration after the 4-month shutdown explains the decadal variations. We also note that both HIRS and AVHRR are only indirect measures of broadband LW flux.

Second, Trenberth suggests that the 36day period required for the ERBS orbit to

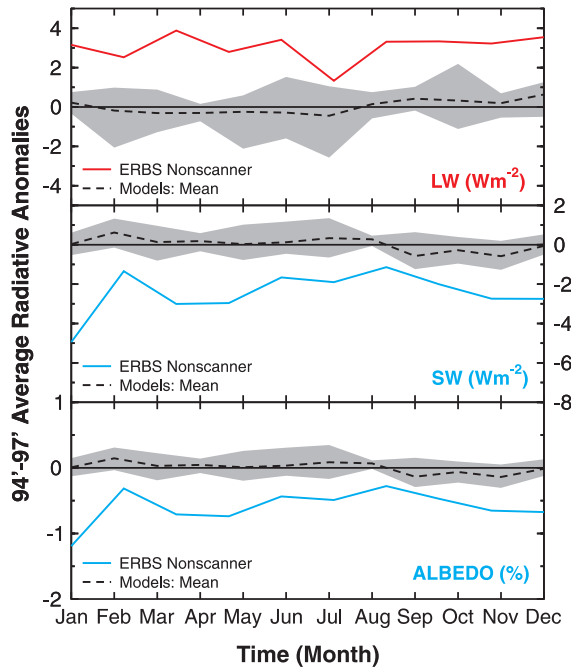

Fig. 1. ERBS satellite 36-day precession cycle averages are used to replace traditional monthly means. These results for tropical mean $\left(20^{\circ} \mathrm{S}\right.$ to $20^{\circ} \mathrm{N}$ ) solar reflected fluxes (SW in blue) and Earth emitted fluxes (LW in red) reduce SW aliasing of diurnal and seasonal cycles and should be compared to figure 3 of (1). The gray region bounds the climate model results. precess through 12 hours of local time sampling could alias diurnal cycle sampling errors into an apparent semiannual cycle change in shortwave (SW) flux. We tested this by constructing 36-day averages instead of monthly means, and found that Trenberth is correct: this removed roughly two-thirds of the semiannual signal. The reason for this error was an interaction between the monthly data processing and a slow drift in the phase of the precession by 6 hours over the period from 1985 to 1995. The 36-day average

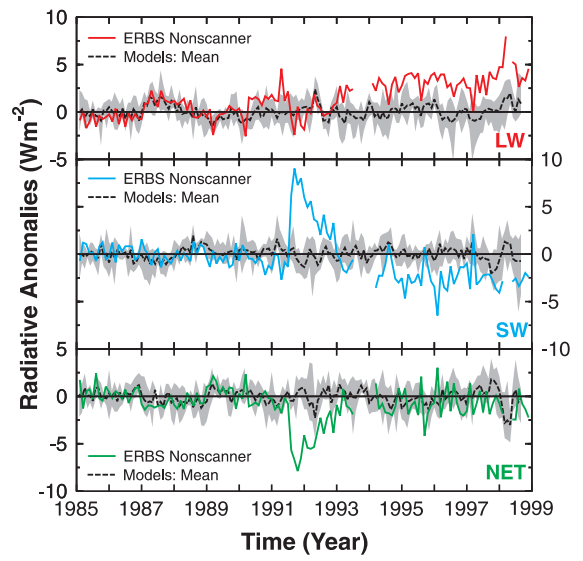

Fig. 2. ERBS satellite 36-day precession cycle averages are used for tropical mean SW, LW, and net radiation anomalies in comparison to climate model simulations. Compare with figure 4 of (1). Elimination of the diurnalcycle aliasing signal results in a clearer decadal radiation signal in SW and net fluxes, although some increased variability in the 1990 s remains.
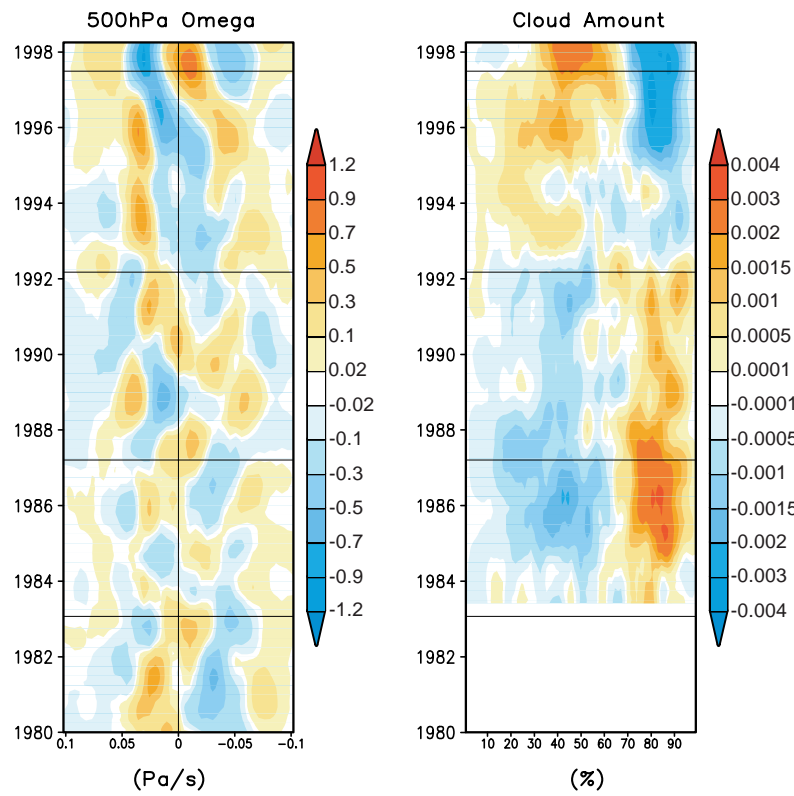

(\%)

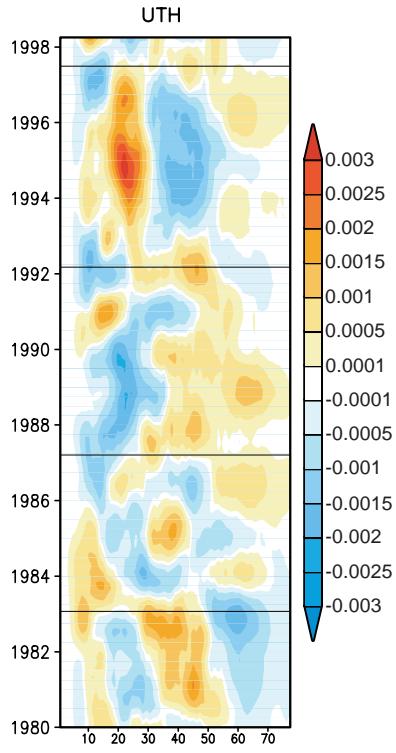

(\%)

Fig. 3. Anomalies in frequency of occurrence of $500 \mathrm{mb}$ vertical velocity (left, Pa $\mathrm{s}^{-1}$ ), cloud amount (\%), and upper troposphere humidity (\%) versus time. Red and blue indicate increased and decreased occurrence, respectively. Major ENSO events are indicated by horizontal lines. Time series are smoothed with a $(1,1.5,2,3,4.5,6.5,8.5,9.5,10.5,11.3,12,12.5,13,12.5,12,11.3,10.5$, $9.5,8.5,6.5,4.5,3,2,1.5,1)$ annual average filter; the $x$ axes are smoothed with a (1-2-4-2-1) filter. 


\section{TECHNICALCOMMENTS}

ERBS anomaly records are shown in Figs. 1 and 2, which should be compared with figures 3 and 4 of (1). The decadal variation in SW flux is now clearer, without a strong seasonal component. Some evidence for increased SW and net flux variability in the 1990s remains.

Third, we agree that interannual variability dominates, as indicated previously (2). The weaker decadal signal emerges only in the frequency domain. We plotted the time series of anomalies in frequency of occurrence of several parameters (Fig. 3). The El Niño-Southern Oscillation (ENSO) weakens the Walker cell, increasing occurrences of near-zero vertical velocity omega, mid- to high-range cloud amount, and midrange upper-troposphere relative humidity (UTH). Decadal variation is seen instead as shifts from near-zero to extreme high and low omega, and from higher to lower cloud amount and UTH, between the 1980s and 1990s. The early to mid-1990s do not resemble ENSO in frequency space. Our decadal subtropical omega $\left(-7.6 \times 10^{-4} \mathrm{~Pa} \mathrm{~s}^{-1}\right)$ and LW flux $\left(-2.8 \mathrm{~W} \mathrm{~m}^{-2}\right)$ changes (2) are each $\sim 1.5 \%$ of their mean values, suggesting that increased subsidence warming balances increased radiative cooling. The observed cloud decrease from 1985-89 to 1996-99, input to a general circulation model (GCM) radiative transfer model, implies a SW flux decrease of 3.0 $\mathrm{W} \mathrm{m}{ }^{-2}$, similar to the $2.5 \mathrm{~W} \mathrm{~m}^{-2}$ decrease observed. Although relationships among the variables in Fig. 3 are complex and require further study, real evidence exists for consistent decadal variation in fluxes and independently observed climate parameters.

Finally, like Trenberth, we also call for more rigorous future observations of climate change. Current global observations are typical- ly designed either for short NASA research missions or for NOAA weather missions at lower accuracy. For example, there is a planned gap in the radiation time series between the end of the NASA Aqua research mission in 2008 and the restart of the National Polar Orbiting Environmental Satellite System (NPOESS) weather system in 2012. Until a continuous climate observing system is established, both climate models and observations will remain uncertain.

Bruce A. Wielicki

NASA Langley Research Center Hampton, VA 23681, USA E-mail: b.a.wielicki@larc.nasa.gov

Anthony D. Del Genio

NASA/Goddard Institute for Space Studies 2880 Broadway

New York, NY 10025, USA

Takmeng Wong

NASA Langley Research Center

Junye Chen

Department of Earth

and Environmental Sciences

Columbia University

Palisades, NY 10964, USA

and NASA/Goddard Institute

for Space Studies

Barbara E. Carlson

NASA/Goddard Institute for Space Studies

Richard P. Allan

Hadley Centre

Met Office

Bracknell, RG12 2SY, UK

Franklin Robertson

NASA Marshall Space Flight Center Huntsville, AL 35812, USA
Herbert Jacobowitz

NOAA/NESDIS

Camp Springs, MD 20746, USA

Anthony Slingo

Hadley Centre

David A. Randall

Colorodo State University

Fort Collins, CO 80523, USA

Jeffrey T. Kiehl

National Center for Atmospheric Research

Post Office Box 3000

Boulder, CO 80303

Brian J. Soden

GFDL/NOAA

Princeton University

Post Office Box 308

Princeton, NJ 08542, USA

C. T. Gordon

GFDL/NOAA

Princeton University

Alvin J. Miller

NOAA Climate Prediction Center/NCEP Camp Springs, MD 20746, USA

Shi-Keng Yang

NOAA Climate Prediction Center/NCEP

Joel Susskind

NASA Goddard Space Flight Center

Huntsville, AL 35812, USA

References

1. B. A. Wielicki et al., Science 295, 841 (2002).

2. J. Chen, B. E. Carlson, A. D. Del Genio, Science 295, 838 (2002)

3. M. R. Luther et al., Appl. Opt. 25, 3705 (1986).

4. C. Frohlich, W. Finsterle, in Recent Insights into the Physics of the Sun and Heliosphere: Highlights from Soho and Other Space Missions, P. Brekke, B. Fleck, J. B. Gurman, Eds. (vol. 203, International Astronomical Union Symposia, Astronomical Society of the Pacific, San Francisco, 2001), p. 105.

21 March 2002; accepted 25 April 2002 